\section{The B.B.C. and the N.H.S.}

SIR,-The B.B.C. could hardly allow the inauguration of the National Health Service to pass without contributing a pep-talk. This took the form of a dramatic discussion in the Light Programme on July 6 at 8.30 p.m. For the benefit of those who missed this enlightenment and inspiration here is a summary.

First we heard a mother's dread of the voluntary hospitals transformed into joyous confidence in the same hospitals nationalized. Then, the existence of the voluntary hospitals being conveniently forgotten, we heard how the wife of a gasworks employee had for years refused surgical treatment to her varicose veins because she could not afford the surgeon's fee.

The hero of the piece was a surgeon basking in his own selfrighteousness, high-mindedness, and other-worldliness. To him came a Mr. Venables, intended to be a typical nouveau riche, or no doubt his modern equivalent, a Tory lower than vermin. He wanted to know whether he should remain a private patient or become a public patient. The hero delivered a moral lecture in the best Pecksniffian manner. But, though eloquent on the evils of the past, he hedged deplorably when questioned about the future. Mr. Venables, seeing through this tirade, decided to remain private. His decision appeared to me to show his astuteness, but the intention of the script writer was evidently the opposite. Incidentally, we heard the old fiction, so sedulously propagated by the Socialists, that the malade imaginaire is found exclusively among the wealthy and that the poor suffer only real illness.

Playing opposite to the hero was the villain, personified of course by the medical superintendent. Trouble had arisen in the bad old days over a case of torticollis, a woman with her neck "twisted right round" (presumably through $180^{\circ}$, not $360^{\circ}$ ). The superintendent was for discharging her, but the hero nobly stood his ground, thereby risking his career in the interests of humanity. Baffled, the superintendent suggested exercises. Again "No" from the hero, who, however, had no suggestion to make except masterly inactivity. The problem was solved by the patient's suddenly dropping down dead. "Tuberculosis of the atlas." Curious that $x$-ray examination twice failed to reveal any abnormality in a neck with the head facing the wrong way. The Light Programme is hardly a place wherein to expect logic. The lesson appeared to be that under the old dispensation a patient with torticollis of unknown cause was discharged from hospital if she survived exercises, but under the new would be left to die in her own way. Believe it or not, the piece was intended to be serious and good propaganda. It is a saddening reflexion that despite the millions spent on its education democracy should be considered, and no doubt is, capable of believing such nonsense.-I am, etc..

Cambridge.

$$
\text { FF. ROBERTS. }
$$

\section{Acute Intussusception}

SIR,- The article by Drs. Brenda Morrison and Donald Court (April 24, p. 776) has brought to mind the six cases of acute intussusception in children and young adults which came under my care during 1947.

Case 1.-A schoolboy, aged about 14 years, had abdominal pain and vomiting of 28 days' duration. Four days before admission each attack was accompanied by defaecation, and the patient had ten motions the day before admission. Helminthiasis was diagnosed and he was given medicine, but did not pass any worms although the bowel moved thrice. The abdomen was rigid and painful to the touch. At operation an entero-colic intussusception about eight inches long was discovered in the left splenic flexure, surrounded by inflamed and adherent omentum. It was irreducible, and as there was apparently no obstruction it was decided that there was no need for any further interference, and the abdomen was closed. The patient gradually recovered and was discharged fit from hospital 24 days after admission, the intussusception having undergone spontaneous cure.

Case 2.-A farmer, aged about 30 years, complained of abdominal pain and vomiting seven days before admission. There was no obstruction and the bowel moved once or twice daily; indeed, it moved five times on the 5th day of admission. Palpation revealed a sausage-shaped abdominal tumour across the epigastrium. At operation an ileo-caecal intussusception was discovered in the epigastrium and was reduced by milking. The caecum and appendix were oedematous. The patient made an uninterrupted recovery. He was discharged 34 days after admission.
Case 3.-A male child, aged 10 years, had abdominal pain and vomiting seven days before admission. In this case also there was no obstruction as the bowels opened three or four times daily in hospital. The abdomen was soft and a sausage-shaped tumour was palpated. An ileo-caecal intussusception was discovered and reduced at operation. The patient made an uninterrupted recovery and was discharged 13 days after admission.

Case 4.-A male child, aged about 12 years, had a history of abdominal pain and vomiting of one month's duration before admission. The patient was very emaciated and dehydrated, due to excessive vomiting. The abdomen was rigid and tender, and the patient was constipated. At operation an irreducible entero-colic intussusception was discovered, with the omentum and the small intestine wrapped round it. As there appeared to be an obstruction in this case a short-circuit operation was performed with a view to resecting the intussusception later, but the patient died 12 hours after the operation.

Case 5.-A schoolboy, aged 8 years, was admitted with pain in the abdomen and vomiting, particularly after food, which started 18 days before admission. Examination revealed a sausage-shaped abdominal tumour across the epigastrium. There was no rigidity, and the patient's condition appeared fair. It was decided to operate at once, and at operation an ileo-caecal intussusception was discovered in the region of the hepatic flexure. It reduced readily by milking, although the caecum appeared very oedematous. This patient died on the third day after operation for no apparent cause.

Case 6.-A 25-years-old male had abdominal pain and vomiting of nine days' duration before admission. He too had a sausageshaped abdominal tumour, but there was no rigidity and no obstruction. An ileo-colic intussusception which occupied the right side of the abdomen was reduced at operation, and the patient made an uninterrupted recovery and was discharged from hospital 25 days after admission. (All the cases were operated on under spinal anaesthesia.)

From a consideration of these cases the following points emerge :

1. Obstruction does not appear to be an early feature of this disease in young adults. Case 4 was the only one with definite obstruction, and in this case there was a history of abdominal pain and vomiting of one month's duration.

2. Although the ileo-ileal variety is generally regarded as being more common after the age of 3 years, the anatomical variety met with in all these cases was the entero-colic type.

3. The passage of blood and mucus, which is regarded as one of the cardinal signs of the disease in children, was not met with in any of the cases.

4. All the patients in this series were male.

5. Acute intussusception is generally regarded as a disease met with in infants up to two years, and in its chronic form in adults -generally over 60 years. Although this series is too small to justify any definite conclusions, it is nevertheless well to bear in mind this condition in considering the differential diagnosis of acute abdominal conditions in children and young adults, at any rate in tropical Africa.

The predisposing factor in these cases is most likely the fact that the African peasants' diet consists mainly of carbohydrates -yams, cassava, and corn-which give rise to fermentation in the large bowel and gaseous distension of the bowel. Any condition which causes violent peristalsis like injudicious diet or violent purgation would drive the ileum into the roomy ascending colon. The late onset of obstruction and gangrene in these cases, and the fact that most of the intussusceptions reduced so easily in spite of their duration, lend support to this theory, as, owing to the width of the colon, the ileum could enter it with part of its mesentery without its blood supply being obstructed.

I am indebted to the Director of Medical Services, Nigeria, for permission to publish these cases

- I am, etc.,

Oshogbo, Nigeria.

\section{A. Majekodunmi.}

SIR,- - I was very interested in the article on acute intussusception in childhood by Dr. Brenda Morrison and Dr. Donald Court (April 24, p. 776), but it was disappointing that they gave so little attention to non-operative treatment in early cases. From force of circumstances I was obliged to try the oldfashioned method of inflation with air on the only two cases I have seen in this remote settlement in northern Canada, with results so dramatically successful that it seems a pity that it should not be tried in all early cases even when facilities for operation are at hand. Since the reduction can be attempted under the anaesthetic given to confirm the presence of the tumour and requires no elaborate equipment or skilled assistance, the loss of time in trying it is very small, and in 